\title{
Active participation at
}

\section{the Modern Language Association's conventions: Why not?}

\author{
By Danielle Mihram \\ Assistant Curator, Bobst Library \\ New York University
}

\section{MLA offers librarians many opportunities.}

$\mathbf{R}$ both the ALA 1985 Annual Conference and the 1986 Midwinter Meeting, have led me to conclude that quite a few members of our Association may not be completely convinced of the pertinence of professional and research concerns that we share with the membership of the Modern Language Association (MLA).

Recurring comments centered around time constraints (library work schedules, and travels to meetings within the library profession precluding supplementary professional concerns); financial hardship (costly membership and convention registration fees, not to mention travel expenses to meetings); and the firm belief among some that our specific interests are not really shared by the MLA membership.

My regular attendance at the annual MLA conventions and my interactions there with libraryoriented members have convinced me of the contrary. I might suggest in passing that the careful selection of one or more additional associations (beyond ALA and ACRL) very closely related to one's own subject specialty may not only broaden our own horizons but also those of the members of that other association who may not be aware of our professional concerns. Admittedly some financial sac- rifice is involved when one considers the additional monetary burden related to memberships, but the professional and intellectual advantages far outweigh such questions.

The date of the MLA annual conventions is constant: December 27-30. The meetings draw huge audiences, approximately ten thousand participants (they constitute the largest meeting of their kind in the humanities) arriving from fifty states as well as from foreign countries. A very large book exhibit is also held at the convention. Over the years the total number of sessions offered has climbed to almost seven hundred (693 in centennial year 1983, 675 in 1984, 661 in 1985) and these range from very small, informal discussion groups to very large forums dealing with topics of broad general interest.

The convention is open to persons who are not members of the association; like members, they must pay a registration fee that recently has risen to $\$ 75$. However, only current MLA members may organize meetings and participate formally in sessions. Occasionally the membership requirement for speakers is waived in the case of invited foreign scholars or individuals with main interests in other disciplines. Membership fees range from low student rates up to $\$ 95$ and these are scaled to the ap- 
plicant's annual income. The first-year membership has a reduced rate of $\$ 25$ as a "get acquainted" enticement. To qualify as a speaker, one must join MLA before April 1 of that convention year.

Details regarding registration at the convention appear each year in the September issue of the $P u b$ lications of the Modern Language Association (PMLA), received as a perquisite of membership. For current information see pp. 433-43 of the September 1985 issue. Calls for papers appear in the Winter and Spring issues of the MLA Newsletter (also a member perquisite), and the convention's "Program Summary" appears one month before the meeting in the November issue. Regrettably there are no printed abstracts or proceedings of the papers presented at the convention, but some authors will mail copies of their papers on request and it is not too uncommon to find in learned periodicals enlarged versions of some of the papers originally presented at the MLA conventions.

Like ALA annual conferences, the site of the convention follows a pattern of rotation and includes such cities as Chicago, New York, San Francisco, and Washington. One can thus plan ahead when the convention is scheduled for a location relatively close to one's place of work or residence. This year's convention will be held in New York and next year's will be held in San Francisco (Chicago was last year's site). Recently ALA and MLA have been choosing the same city each year.

Of mutual interest to both ACRL and MLA memberships are topics that relate to the gathering and dissemination of research, particularly in the fields of language, literature, and literary criticism, though not exclusively, since computers, performing arts, science, sociology, and religion-to name just a few-are also represented in the many divisions of the MLA. Papers by ACRL members on specialized subjects, perhaps with an emphasis on bibliographical information along the lines of papers appearing in the WESS Newsletter, for example, should be well received.

One advantage that we have in the compilation of information and the preparation for such papers is our own expertise in database searching and our knowledge of the scope of databases other than that of the MLA online: e.g., the Arts and Humanities Citation Index, now online via BRS; the various databases in history, philosophy, religion, and the social sciences; the French database, QUESTEL, which can be searched in English and provides bibliographic information on research in both Eastern and Western Europe. The Spring 1986 issue of the MLA Newsletter (p. 23) includes a short article on the availability of HumaNet, an electronic networking service for scholars in the humanities that was developed at North Carolina State University, where PoliNet, a service for political scientists, is already in operation. Walter Meyers, professor of English at North Carolina State, will direct and coordinate HumaNet, which initially will serve researchers in English, history, and religion. The ad- vantage of the system is its ability to link scholars in 65 countries.

Some of the following sessions at the 1985 MLA convention would have been appropriate for a paper from an ACRL member, particularly on research or bibliography: "The Revival of the Baroque in Turn-of-the-Century Austrian Literature" (special session); "Chicano Literature: Past, Present, and Future" (Discussion Group on Chicano Literature); "New Critical Approaches to Francophone Literature" (Division on French Literature Outside Europe); and "Introducing Asian Literature to Undergraduates" (Division on Asian Literature).

Directly relevant to our own field were such sessions as: "Libraries and Learned Journals: A Statement of Common Concern," where one of the speakers was Helen F. Schmierer, Acquisition Services, University of Chicago, paralleling a session organized and chaired by myself in 1983: "Today's Academic Libraries and University Presses: Their Role in Modern Language Studies." Another interesting session last year was: "Bibliographical Data Bases in Literary Research: The View from Here," with one panelist being Eileen M. Mackesy, of the MLA Center for Bibliographical Services. A librarian's "View from Here" may well have given a broader scope to the session since the only other two panelists were professors in Departments of English.

Broader perspectives might also be obtained from sessions dealing with special collections. One noteworthy session was "Renaissance Libraries: Catalogs in Progress," with papers dealing with the compilation of catalogs of several collections: those of Philip Sidney (Victoria Collection, University of Toronto), John Dee (Bodleian Library, Oxford University), Ben Jonson (University Collection, University of London), and Robert Burton (Washington State University).

The 1984 convention included several topics equally relevant to both ACRL and MLA members. Two sessions relating specifically to women's studies were held: "Women's Magazines: Past" and "Women's Magazines: Present." The session, "Beyond Bibliographies and Concordances: The Use of On-line Data Bases in Modern Language Research," which I organized and chaired, presented a broad spectrum of viewpoints, including those of librarian Geoffrey D. Smith, Ohio State University, who spoke on the "Scholarly Access to American Fiction, 1901-25: Present Capabilities and Fu-

\section{Affiliation omitted}

In the "ALA Candidates on ACRL" statements that appeared in the April issue of $C \& R L$ News, candidate Charles W. Robinson's affiliation was inadvertently left out. Robinson is director at Baltimore County Public Library, Towson, Maryland. 
ture Applications [of a new database]," as well as my own topic, "Literary Criticism and MachineReadable Texts: Projects for the Future." The literary side of that session was covered by Robert I. Allen (Rutgers University) who discussed machine-readable literary texts and their stylostatistical analysis, and Robert Pontario (St. Lawrence University) who reported on a machinereadable library of works by Charles Nodier available on microcomputer-compatible disks. G.D. Smith has issued a call for papers for a session at MLA in 1986: "Creative Literary Research Using On-Line Bibliographic Data Bases."

In February 1985 MLA made available to its membership a word-processing software package and text-base program developed by Dragonfly Software (see Phyllis Franklin's article in the Spring 1986 MLA Newsletter, pp. 3-4).

MLA conventions include four distinct types of sessions: Division meetings, Discussion Groups, Forums, and Special Sessions. The first two represent major and smaller areas of interest respectively and each is run by an executive committee. They usually organize up to three annual formal programs. Proposals for the arrangement of Forums (public meetings on topics of broad general interest) must be approved by the MLA executive director and Program Committee. It is recommended that interested members attend the open meeting of that committee during the convention preceding such proposals. Three Forums are planned for 1986.

Special Sessions cover specific topics not covered by other programs. They involve a session leader (or chair) and a panel of speakers. Guidelines for the submission of proposals for Special Sessions appear in the September issue of the PMLA and the calendar of deadlines is announced in the Winter MLA Newsletter. Papers may be solicited from the membership via the "Call for Papers" published in the Newsletter; or individuals may form a group (not more than four speakers per session to allow adequate presentation time), select a session leader, and present a proposal for a special session. Ideally a session should include speakers from both the library world and the MLA membership. The MLA Program Committee prefers a panel of speakers from different institutions, but exceptions may be made if the topic discussed centers on work accomplished at one site. Forms for the submission of proposals for Special Sessions are available from the MLA Convention Office, 10 Astor Place, New York, NY 10003, or at MLA information booths at the convention. Librarians interested in proposing sessions may also explore the possibility of inserting their own "call for papers" in appropriate ACRL section newsletters.

Active participation at the MLA? Why not?

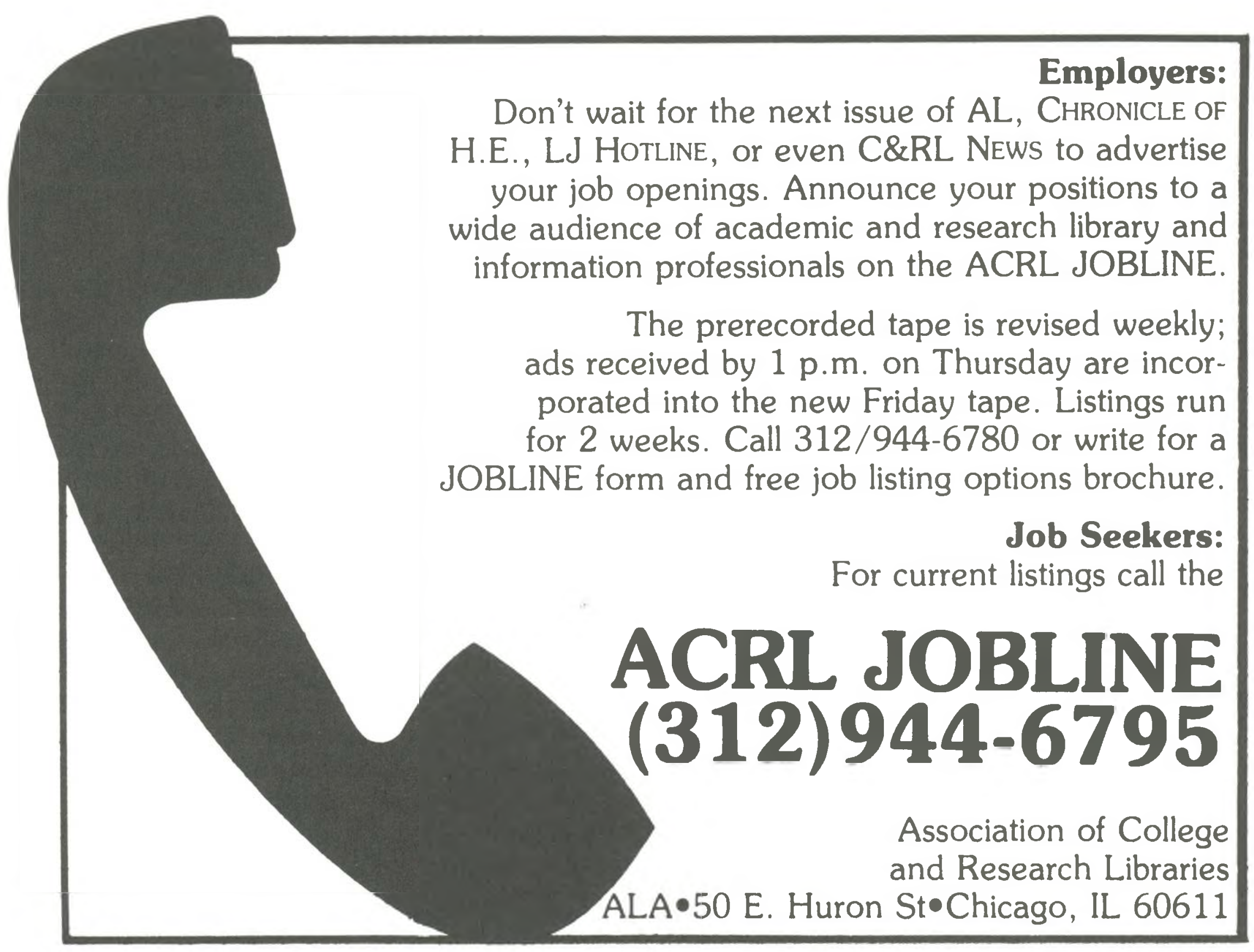

